\title{
Application of Mid-Frequency Ventilation in an Animal Model of Lung Injury: A Pilot Study
}

\author{
Eduardo Mireles-Cabodevila MD, Robert L Chatburn MHHS RRT-NPS FAARC, \\ Tracy L Thurman, Luis M Zabala MD, Shirley J Holt RRT, \\ Christopher J Swearingen PhD, and Mark J Heulitt MD
}

\begin{abstract}
BACKGROUND: Mid-frequency ventilation (MFV) is a mode of pressure control ventilation based on an optimal targeting scheme that maximizes alveolar ventilation and minimizes tidal volume $\left(V_{T}\right)$. This study was designed to compare the effects of conventional mechanical ventilation using a lung-protective strategy with MFV in a porcine model of lung injury. Our hypothesis was that MFV can maximize ventilation at higher frequencies without adverse consequences. We compared ventilation and hemodynamic outcomes between conventional ventilation and MFV. METHODS: This was a prospective study of 6 live Yorkshire pigs $(10 \pm 0.5 \mathrm{~kg})$. The animals were subjected to lung injury induced by saline lavage and injurious conventional mechanical ventilation. Baseline conventional pressure control continuous mandatory ventilation was applied with $V_{T}=6 \mathrm{~mL} / \mathrm{kg}$ and PEEP determined using a decremental PEEP trial. A manual decision support algorithm was used to implement MFV using the same conventional ventilator. We measured $\mathrm{P}_{\mathrm{aCO}}, \mathrm{P}_{\mathrm{aO}}$, end-tidal carbon dioxide, cardiac output, arterial and venous blood oxygen saturation, pulmonary and systemic vascular pressures, and lactic acid. RESULTS: The MFV algorithm produced the same minute ventilation as conventional ventilation but with lower $V_{T}(-1 \pm 0.7 \mathrm{~mL} / \mathrm{kg})$ and higher frequency $(32.1 \pm 6.8$ vs $55.7 \pm 15.8$ breaths $/ \mathrm{min}, P<.002)$. There were no differences between conventional ventilation and MFV for mean airway pressures $\left(16.1 \pm 1.3 \mathrm{vs} 16.4 \pm 2 \mathrm{~cm} \mathrm{H}_{2} \mathrm{O}\right.$, $P=.75)$ even when auto-PEEP was higher $\left(0.6 \pm 0.9\right.$ vs $\left.2.4 \pm 1.1 \mathrm{~cm} \mathrm{H}_{2} \mathrm{O}, P=.02\right)$. There were no significant differences in any hemodynamic measurements, although heart rate was higher during MFV. CONCLUSIONS: In this pilot study, we demonstrate that MFV allows the use of higher breathing frequencies and lower $V_{T}$ than conventional ventilation to maximize alveolar ventilation. We describe the ventilatory or hemodynamic effects of MFV. We also demonstrate that the application of a decision support algorithm to manage MFV is feasible. Key words: mechanical ventilation; lung injury; auto-PEEP; hemodynamic; algorithms; pulmonary gas exchange; decision support; ventilation protocol; optimum ventilation; targeting scheme. [Respir Care 2014;59(11):1619-1627. (C) 2014 Daedalus Enterprises]
\end{abstract}

\section{Introduction}

Mid-frequency ventilation (MFV) is a new mode of ventilation based on a unique form of optimal targeting

Dr Mireles-Cabodevila and Mr Chatburn are affiliated with the Respiratory Institute, Cleveland Clinic, Cleveland, Ohio. Ms Thurman and Dr Heulitt are affiliated with the Section of Pediatric Critical Care Medicine, College of Medicine, University of Arkansas for Medical Sciences, Little Rock, Arkansas. Dr Zabala is affiliated with the Department of Anesthesiology, University of Texas Southwestern Medical Center at Dallas, and the Children's Medical Center of Dallas, Dallas, Texas. Ms Holt is scheme $^{1}$ that maximizes alveolar ventilation and minimizes tidal volume $\left(\mathrm{V}_{\mathrm{T}}\right)$ while being responsive to changes in lung mechanics. ${ }^{2,3}$ MFV capitalizes on the properties of a pressure control breath and its response to changes in ven-

affiliated with the Department of Respiratory Care, Arkansas Children's Hospital, Little Rock, Arkansas. Dr Swearingen is affiliated with the Biostatistics Program, Department of Pediatrics, College of Medicine, University of Arkansas for Medical Sciences, and the Arkansas Children's Hospital, Little Rock, Arkansas. At the time of this study, Dr Mireles-Cabodevila was affiliated with the University of Arkansas for Medical Sciences, Little Rock, Arkansas. 
tilatory frequency. The theoretical basis of MFV has been explained in detail elsewhere. ${ }^{3}$ It is classified as a form of pressure control continuous mandatory ventilation (CMV) with set-point targeting. Briefly, during ventilation of a passive subject with pressure control breaths, $\mathrm{V}_{\mathrm{T}}$ is a function of set inspiratory pressure (above PEEP), set inspiratory and expiratory times, and both inspiratory and expiratory time constants. ${ }^{4,5}$ If frequency is increased while keeping inspiratory pressure and inspiratory-expiratory ratio (I:E) constant, the $\mathrm{V}_{\mathrm{T}}$ will decrease due to a shortened inspiratory time and the development of a low level of auto-PEEP. However, the decrease in $\mathrm{V}_{\mathrm{T}}$ is offset by the increase in frequency such that the minute ventilation rises asymptotically (ie, beyond a certain point, a further increase in frequency produces no meaningful increase in minute ventilation). ${ }^{5}$ However, alveolar minute ventilation behaves differently. Alveolar ventilation is a function of $\mathrm{V}_{\mathrm{T}}$ and dead space. If dead space remains relatively constant, ${ }^{6,7}$ then as frequency increases and $V_{T}$ decreases, the alveolar minute ventilation will increase and then decrease, ${ }^{3}$ thus showing a local maximum value. We termed the frequency at which alveolar ventilation is maximal the optimum frequency.

\section{SeE the Related Editorial on Page 1808}

In our preliminary studies, the optimum frequency was higher and resulted in lower $\mathrm{V}_{\mathrm{T}}$ than conventional modes for the same level of ventilation. However, the optimum frequency was not as high as that produced by specialized high-frequency ventilators (high-frequency jet ventilators and high-frequency oscillatory ventilators); hence, we named this new mode mid-frequency ventilation. Moreover, because this is a pressure control mode at a constant $\mathrm{I}: \mathrm{E}$, the peak inspiratory pressure and mean airway pressure remain constant as frequency changes. ${ }^{3,5,8,9}$ These findings are of particular clinical relevance, as the current practice is to limit ventilatory frequency to prevent the ill effects of auto-PEEP on hemodynamics and gas exchange. ${ }^{10,11}$ However, mathematical models and physical lung simulators do not reflect the complex mechanics of

\footnotetext{
This research was supported by an institutional grant from the Children's University Medical Group Award Program. Dr Mireles-Cabodevila and Mr Chatburn co-own the patent on MFV. Mr Chatburn is a consultant for Covidien, Dräger, IngMar Medical, Philips, and Hamilton. The other authors have disclosed no conflicts of interest.
}

Correspondence: Eduardo Mireles-Cabodevila MD, Respiratory Institute, Cleveland Clinic Foundation, 9500 Euclid Avenue G62, Cleveland, OH 44195. E-mail: mirelee@ccf.org.

DOI: $10.4187 /$ respcare. 03105

\section{QUICK LOOK}

\section{Current knowledge}

Mid-frequency ventilation (MFV) is a pressure control method of mechanical ventilation that allows the delivery of small tidal volumes $\left(\mathrm{V}_{\mathrm{T}}\right)$ and rapid breathing frequencies with conventional mechanical ventilators. No animal or human trials have been accomplished to date.

\section{What this paper contributes to our knowledge}

In a paralyzed porcine pediatric model of acute respiratory failure, MFV allowed the use of higher breathing frequencies and lower $\mathrm{V}_{\mathrm{T}}$ than conventional ventilation to maximize alveolar ventilation over a short period of observation. Hemodynamic consequences were similar, although animals treated with MFV experienced a $40 \%$ increase in heart rate.

real lung-ventilator systems, nor do they reflect the effects of mechanical ventilation on hemodynamics. Therefore, this study was designed to compare the effects of conventional mechanical ventilation using a lung-protective strategy with MFV in a porcine model. Our hypothesis was that MFV results in the benefits predicted by our previous studies without adverse consequences. Specifically, we sought to compare ventilatory parameters, hemodynamic parameters, and blood gas values between conventional ventilation and MFV.

\section{Methods}

The Institutional Animal Care and Use Committee of the Arkansas Children's Hospital Research Institute approved this study. All research was conducted at the Applied Respiratory Physiology Laboratory, Arkansas Children's Hospital, and the University of Arkansas for Medical Sciences, Little Rock, Arkansas. The study was designed to demonstrate that maximizing alveolar ventilation and minimizing $\mathrm{V}_{\mathrm{T}}$ are achievable in a model of acute lung injury using a MFV algorithm to identify optimum settings. We compared conventional lung-protective ventilation at stable baseline settings to MFV at optimum settings.

\section{Animal Model Preparation}

Two-week-old male Yorkshire pigs had constant intravenous anesthesia, analgesia, and neuromuscular blockade with fentanyl $(5 \mu \mathrm{g} / \mathrm{kg} / \mathrm{h})$, propofol $(3 \mathrm{mg} / \mathrm{kg} / \mathrm{h})$, and vecuronium (0.3-0.7 mg/kg/h). A lactated Ringer solution 
$(10 \mathrm{~mL} / \mathrm{kg}$ bolus, repeated twice if needed to stabilize vital signs) was given at initiation of the study, followed by a maintenance infusion of $4 \mathrm{~mL} / \mathrm{kg} / \mathrm{h}$. The left internal jugular was cannulated with a 5 French triple-lumen catheter (Cook Medical, Bloomington, Indiana). The left carotid was cannulated with a 4-5 French single-lumen catheter (Cook Medical). The pulmonary artery was cannulated via the right internal jugular with a pulmonary artery catheter (4 French thermodilution balloon catheter, Arrow International, Reading, Pennsylvania). Animals were intubated with a cuffed endotracheal tube (5.0-6.0-mm inner diameter). The cuff was inflated to a minimum occlusion pressure. ${ }^{12}$ Mechanical ventilation was delivered with a Servo-i ventilator (Maquet, Wayne, New Jersey) with a heated wire circuit (RS240, Fisher \& Paykel Healthcare, Auckland, New Zealand) and a heated humidifier (MR290 humidification system, Fisher \& Paykel Healthcare). An expiratory carbon dioxide monitor used to measure end-tidal carbon dioxide (Maquet) was placed at the proximal end of the endotracheal tube.

\section{Experimental Protocol}

Lung Injury. After the pig had stabilized, the lungs were lavaged in the supine and alternating lateral decubitus positions with 3 aliquots $(30 \mathrm{~mL} / \mathrm{kg})$ of isotonic saline at $38^{\circ} \mathrm{C}$. Injurious ventilatory settings $\left(\mathrm{V}_{\mathrm{T}}=20 \mathrm{~mL} / \mathrm{kg}\right.$ and zero PEEP) were maintained for 30-min intervals until lung compliance (after a recruitment maneuver) was $\sim 50 \%$ from baseline.

Baseline Conventional Ventilation. All animals were ventilated with pressure control CMV. Inspiratory rise time was set at $0 \mathrm{~ms}$. The inspiratory pressure above PEEP was set to deliver a $V_{T}$ of $6 \mathrm{~mL} / \mathrm{kg}$. The I:E was $1: 1$. The baseline ventilatory frequency was adjusted to achieve a $\mathrm{P}_{\mathrm{aCO}_{2}}$ of $40 \pm 5 \mathrm{~mm} \mathrm{Hg}$, but was kept below 35 breaths $/ \mathrm{min}$. Set PEEP was based on the trend of volumetric carbon dioxide and dynamic characteristic using the Open Lung Tool function of the Servo-i ventilator. ${ }^{13}$ The maneuver to set PEEP was a recruitment phase, followed by a decremental PEEP phase. The recruitment phase started with a stepwise increase of PEEP to $12-14 \mathrm{~cm} \mathrm{H}_{2} \mathrm{O}$ (increments of $2 \mathrm{~cm} \mathrm{H}_{2} \mathrm{O}$ ) and increasing inspiratory pressure (above PEEP) in steps of $2 \mathrm{~cm} \mathrm{H}_{2} \mathrm{O}$ while monitoring volumetric tidal carbon dioxide elimination and dynamic characteristic in a graphic display. The point where the volumetric carbon dioxide elimination peaked or reached a plateau was considered to be the point of maximum recruitment. Then, the $V_{T}$ was decreased to baseline $(6 \mathrm{~mL} / \mathrm{kg})$ by decreasing the inspiratory pressure. We proceeded to the decremental PEEP phase, where PEEP was lowered by $1 \mathrm{~cm} \mathrm{H}_{2} \mathrm{O}$ every $4-6$ breaths until dynamic characteristic decreased (interpreted as alveolar collapse). At that point, a recruitment phase was repeated, and the PEEP level was set at $2 \mathrm{~cm} \mathrm{H}_{2} \mathrm{O}$ above the previously identified point of alveolar collapse. This maneuver was repeated after each ventilator disconnection or de-recruitment event.

The settings were maintained for $20 \mathrm{~min}$ before obtaining measurements and proceeding to the next study phase. The $\mathrm{F}_{\mathrm{IO}_{2}}$ was 1.0 and was not changed through the experiment. Once hemodynamic stability was achieved, the settings were maintained for $60 \mathrm{~min}$ before obtaining measurements and proceeding to MFV.

MFV Ventilation Using a Decision Support Algorithm. MFV was managed with an explicit algorithm (Fig. 1). MFV was implemented as pressure control CMV with a conventional ventilator (Servo-i). The algorithm advises manual adjustment of ventilatory frequency, I:E, inspiratory pressure, and PEEP following the MFV strategy. Each step in the algorithm was dictated by the response in alveolar ventilation (assessed in terms of $\mathrm{P}_{\mathrm{aCO}_{2}}$ ) to a ventilatory change. The target $\mathrm{P}_{\mathrm{aCO}}$ was $40 \pm 2 \mathrm{~mm} \mathrm{Hg}$. Arterial blood gases were drawn 10 min after each ventilatory change, and this dictated the next change in settings. Optimum settings were reached when a step repeated itself in the algorithm (same instruction after a change). This resulted in a set of frequency, I:E, and airway pressures that were considered to be optimized. The optimum settings were then continued for $60 \mathrm{~min}$. Measurements were obtained at the end of the 60 min on optimum MFV settings.

Measurements. The respiratory system characteristics (resistance and compliance) were obtained by quasi-static pressure-volume curves and the forced oscillation technique (flexiVent, Scireq, Montreal, Canada) before and after lung injury. ${ }^{14}$

The ventilatory output $\left(\mathrm{V}_{\mathrm{T}}\right.$, airway pressures relative to atmospheric pressure, breathing frequency, resistance and compliance calculations, and end-tidal carbon dioxide) was continuously recorded and downloaded to a removable memory card in the Servo-i. End-expiratory airway pressure was continuously measured and recorded. The level of auto-PEEP was measured after a 2-s expiratory pause and recorded from the monitor.

Hemodynamic measurements, including heart rate, systemic, venous and pulmonary artery pressures, pulse rate, and core temperature (pulmonary artery catheter), were continuously recorded via a physiologic monitor (SC 9000X, Siemens, Berlin, Germany). Cardiac output was determined by averaging 3 measurements obtained after the injection of $3 \mathrm{~mL}$ of iced isotonic solution through the proximal port of the pulmonary artery catheter. Arterial blood gases were obtained with a minimum blood draw technique and analyzed with an i-STAT analyzer (Abbot, Princeton Point of Care, New Jersey). 


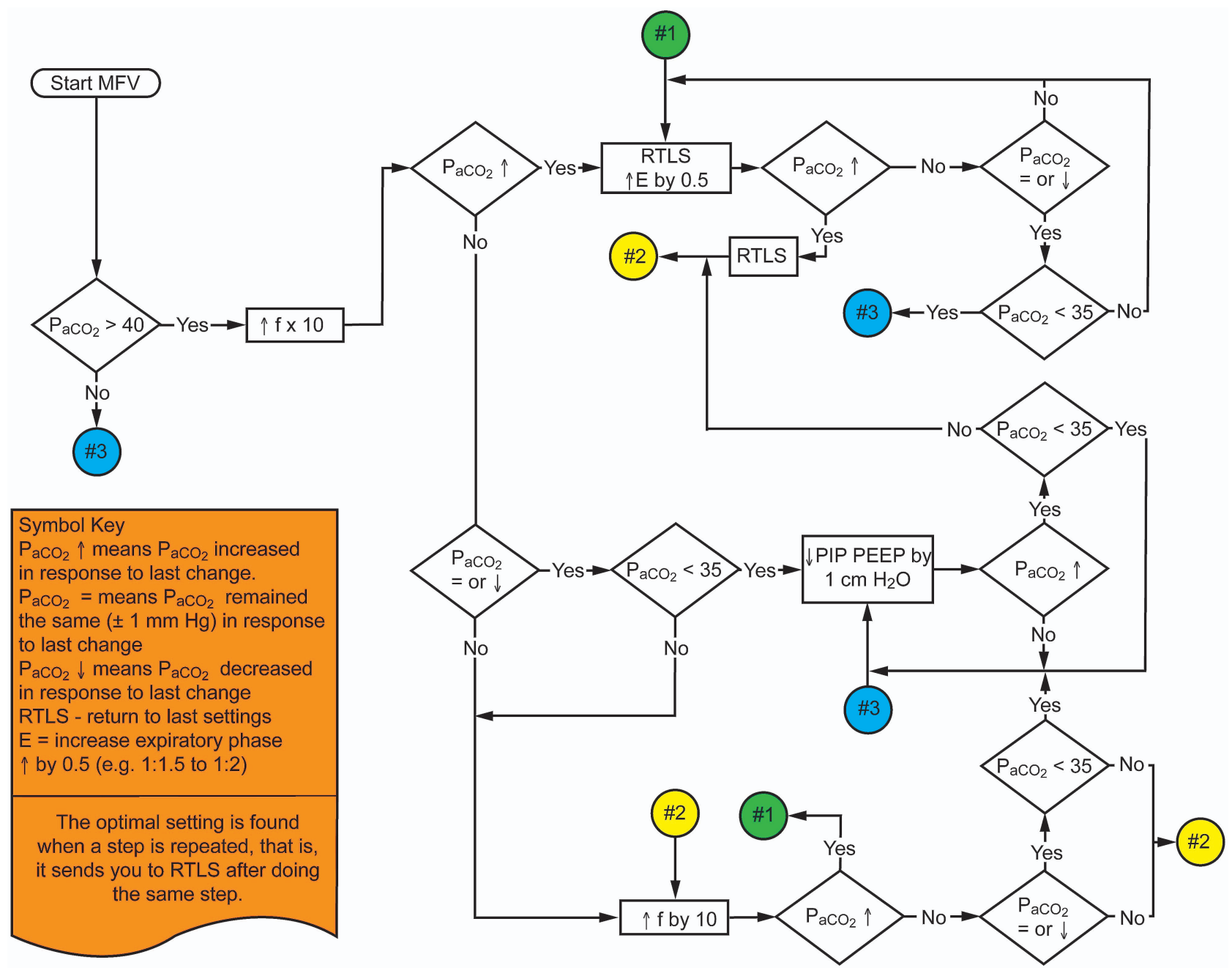

Fig. 1. Mid-frequency ventilation (MFV) representative management algorithm. The process starts with increasing frequency. The response assessed for each step is the change in $\mathrm{P}_{\mathrm{acO}}$. The change in $\mathrm{P}_{\mathrm{acO}}$ dictates the next step. Predefined goals for each step are followed. The optimum setting is found once a step is repeated, ie, one reaches return to last setting (RTLS) after repeating a step. $\uparrow E=$ increase in expiratory phase by 0.5 ; PIP $=$ peak inspiratory pressure; $f=$ frequency (breaths $/ \mathrm{min}$ ).

\section{Statistical Analysis}

Summary statistics (eg, mean \pm SD) at postinjury baseline were estimated for ventilation, hemodynamic, and blood gas values. Change was calculated for each variable as values at optimum frequency minus values at baseline. Significant change was evaluated using Wilcoxon signedrank tests for paired observations, or a regression model adjusting for baseline measures was used to determine whether a statistically significant change existed between ventilation groups. Additionally, a repeated-measures analysis was conducted to assess change over time in ventilation, hemodynamic, and blood gas values between MFV and conventional mechanical ventilation groups. Regression models assessed change in outcomes between groups accounting for time elapsed (in min) since the postinjury baseline as well as repeated measures on each animal. All analysis was completed using Stata 12.0 (StataCorp, College Station, Texas).

\section{Results}

Six 2-week-old male Yorkshire pigs (mean weight $10 \pm 0.5 \mathrm{~kg}$ ) were studied. After induction of lung injury, the lung static compliance dropped from $21.4 \pm 2.9$ to $12.9 \pm 3.7 \mathrm{~mL} / \mathrm{cm} \mathrm{H}_{2} \mathrm{O}$.

Table 1 presents a representative progression of a study animal through the protocol. During CMV, the inspiratory pressure had to be adjusted to maintain a $\mathrm{V}_{\mathrm{T}}$ of $6 \mathrm{~mL} / \mathrm{kg}$. At the initiation of MFV (ie, end of $1 \mathrm{~h}$ of CMV), the $\mathrm{P}_{\mathrm{aCO}_{2}}$ was elevated to $50.2 \pm 8.5 \mathrm{~mm} \mathrm{Hg}$. The rate was adjusted (to a maximum rate of $35 \mathrm{bpm}$ ) before initiation of the 
Table 1. Representative Progression of a Study Animal Through the MFV Protocol

\begin{tabular}{|c|c|c|c|c|c|c|c|c|c|c|c|}
\hline \multirow[b]{2}{*}{$\begin{array}{l}\text { Time From } \\
\text { Last Step* }\end{array}$} & \multirow[b]{2}{*}{ Study Phase } & \multicolumn{5}{|c|}{ Ventilatory Settings } & \multicolumn{5}{|c|}{ Ventilatory Outcomes } \\
\hline & & $\begin{array}{c}\text { Breathing } \\
\text { Frequency } \\
\text { (breaths/min) }\end{array}$ & $\mathrm{I}: \mathrm{E}$ & $\mathrm{T}_{\mathrm{I}}(\mathrm{s})$ & $\begin{array}{c}\text { Set PIP } \\
\left(\mathrm{cm} \mathrm{H} \mathrm{H}_{2} \mathrm{O}\right)\end{array}$ & $\begin{array}{l}\text { Set PEEP } \\
\left(\mathrm{cm} \mathrm{H}_{2} \mathrm{O}\right)\end{array}$ & $\begin{array}{c}\mathrm{V}_{\mathrm{T}} \\
(\mathrm{mL} / \mathrm{kg})\end{array}$ & $\begin{array}{c}\mathrm{P}_{\mathrm{aCO}_{2}} \\
(\mathrm{~mm} \mathrm{Hg})\end{array}$ & $\begin{array}{c}\mathrm{P}_{\mathrm{ETCO}_{2}} \\
\text { (mm Hg) }\end{array}$ & $\begin{array}{c}\mathrm{MV} \\
(\mathrm{L} / \mathrm{min})\end{array}$ & $\begin{array}{c}\text { Mean Airway } \\
\text { Pressure } \\
\left(\mathrm{cm} \mathrm{H}_{2} \mathrm{O}\right) \\
\end{array}$ \\
\hline $0 \mathrm{~min}$ & Healthy baseline $\dagger$ & 25 & $1: 1$ & 1.18 & 11 & 5 & 6.5 & 42.5 & 55 & 1.58 & 8 \\
\hline $60 \mathrm{~min}$ & Baseline after lung injury & 20 & $1: 1$ & 1.47 & 16 & 10 & 6.3 & 41.7 & 41 & 1.24 & 14 \\
\hline $60 \mathrm{~min}$ & $\mathrm{CV}$ after $1 \mathrm{~h}$ & 20 & $1: 1$ & 1.47 & $17-22$ 末 & 10 & 5.7 & 63.5 & 59 & 1.1 & 15 \\
\hline $20 \mathrm{~min}$ & MFV at start & 35 & $1: 1$ & 0.86 & 22 & 10 & 5.7 & 46.9 & 47 & 1.9 & 15 \\
\hline $14 \mathrm{~min}$ & MFV algorithm step & $45 \S$ & $1: 1$ & 0.67 & 22 & 10 & 6.1 & 38.8 & 38 & 2.6 & 15 \\
\hline $14 \mathrm{~min}$ & MFV algorithm step & $55 \S$ & $1: 1$ & 0.55 & 22 & 10 & 5.6 & 36.9 & 37 & 3.1 & 15 \\
\hline $14 \mathrm{~min}$ & MFV algorithm step & $65 \S$ & $1: 1$ & 0.47 & 22 & 10 & 5.3 & 35.2 & 36 & 3.31 & 15 \\
\hline $14 \mathrm{~min}$ & MFV algorithm step & $75 \S$ & $1: 1$ & 0.4 & 22 & 10II & 4II & 46.5 & 45 & 2.79 & 16 \\
\hline $14 \mathrm{~min}$ & MFV algorithm step & $65 \S$ & $1: 1.5 \S$ & 0.37 & 22 & 11 & 4.8 & 41 & 37 & 3.1 & 16 \\
\hline $14 \mathrm{~min}$ & MFV algorithm step & 65 & $1: 2 \S$ & 0.31 & 23 & 11 & 5 & 40.9 & 37 & 3.1 & 15 \\
\hline $14 \mathrm{~min}$ & MFV algorithm step & $65 \|$ & $1: 2.5 \S$ & $0.26 \|$ & $22 \|$ & $11 \|$ & $4.6 \|$ & $38.2 \|$ & $37 \|$ & $3.09 \|$ & $14 \|$ \\
\hline $14 \mathrm{~min}$ & MFV algorithm step & 65 & $1: 3 \S$ & 0.23 & 22 & 11 & 4.5 & 42.9 & 40 & 2.76 & 14 \\
\hline $14 \mathrm{~min}$ & MFV algorithm step & $75 \S$ & $1: 2.5 \S$ & 0.23 & 22 & 11 & 3.9 & 44.5 & 43 & 3 & 14 \\
\hline NA & Start of Optimum settings & 65 & $1: 2.5$ & 0.26 & 22 & 11 & NA & NA & NA & NA & NA \\
\hline $60 \mathrm{~min}$ & $1 \mathrm{~h}$ after optimum MFV & 65 & $1: 2.5$ & 0.26 & 22 & 11 & 4.3 & 49.2 & 44 & 2.44 & 14 \\
\hline $\begin{array}{l}\text { Pig weight was } \\
* \text { Approximate ti } \\
\text { † Ventilator setti } \\
\text { † Inspiratory pre } \\
\text { \& Changes in ver } \\
\text { \| Optimum settin } \\
\text { II Rate-related de } \\
\mathrm{I}: \mathrm{E}=\text { inspiratory } \\
\mathrm{T}_{\mathrm{I}}=\text { inspiratory } \\
\mathrm{PIP}=\text { peak inspi } \\
\mathrm{P}_{\mathrm{ETCO}}=\text { end-tic } \\
\mathrm{MV}=\text { minute ve } \\
\mathrm{CV}=\text { conventiol } \\
\mathrm{NA}=\text { not applic }\end{array}$ & $\begin{array}{l}9.2 \mathrm{~kg} . \\
\text { imes } \\
\text { ings before lung injury were PEEP } 5 \\
\text { ssure was adjusted during convention } \\
\text { ntilatory settings according to the alg } \\
\text { ngs for mid-frequency ventilation (MP } \\
\text {--recruitment } \\
\text { y-expiratory ratio } \\
\text { time } \\
\text { iratory pressure above atmospheric pr } \\
\text { dal } \mathrm{P}_{\mathrm{CO}} \\
\text { entilation (exhaled) } \\
\text { nal ventilation } \\
\text { cable }\end{array}$ & $\begin{array}{l}\mathrm{cm} \mathrm{H}_{2} \mathrm{O} \text { and } \mathrm{F}_{\mathrm{IO}_{2}} 0 \text {. } \\
\text { al ventilation to mai } \\
\text { orithm in response to } \\
\mathrm{FV} \text { ) protocol. }\end{array}$ & $\begin{array}{l}3 . \\
\text { intain the } \mathrm{t} \\
\mathrm{o}_{\mathrm{aCO}} \mathrm{e}\end{array}$ & $\begin{array}{l}\text { idal volun } \\
\text { els. }\end{array}$ & ne $\left(\mathrm{V}_{\mathrm{T}}\right)$ at target & & & & & & \\
\hline
\end{tabular}

MFV protocol to achieve the target $\mathrm{P}_{\mathrm{aCO}}$. It took an average of 6.8 (range 3-10) steps (Table 1, values indicated by $\S$ ) in the MFV algorithm to achieve the optimum MFV settings (values indicated by II). The II symbols highlight events where, after a frequency increase, there is a sudden drop in $\mathrm{V}_{\mathrm{T}}$ (beyond what was expected). We termed these events rate-related de-recruitment. They happened mainly at higher than optimum rates. From our previous experience, these are controlled with a recruitment maneuver and an increase of PEEP (see the rise of $1 \mathrm{~cm} \mathrm{H}_{2} \mathrm{O}$ on the set PEEP in Table 1).

Table 2 summarizes the ventilation and hemodynamic outcomes. The optimum frequency was 24 breaths/min above conventional lung-protective ventilation (55.7 vs 32.1 breaths $/ \mathrm{min}, P=.035$ ), which resulted in a $1 \mathrm{~mL} / \mathrm{kg}$ reduction in $\mathrm{V}_{\mathrm{T}}$, and the $\mathrm{P}_{\mathrm{aCO}}$ was lower than at baseline. After $1 \mathrm{~h}$ of ventilation with the optimum MFV settings (where no changes were made), the $\mathrm{P}_{\mathrm{aCO}}$ was higher than baseline conventional ventilation, but the difference was not statistically significant. The mean and peak airway pressures remained constant, whereas the total PEEP increased. The auto-PEEP measured after an expiratory pause was $1.4 \mathrm{~cm} \mathrm{H}_{2} \mathrm{O}$ higher on MFV (0.6 vs $2.4, P=.02$ ).
There was an increase in airway PEEP of $\sim 1 \mathrm{~cm} \mathrm{H}_{2} \mathrm{O}$ due to the decrease in expiratory time. There was no statistically significant hemodynamic change when comparing MFV and conventional lung-protective ventilation. However, the heart rate was higher upon achieving the optimum MFV settings, and, although it decreased, it remained higher after $1 \mathrm{~h}$ of MFV.

We evaluated the change in hemodynamic and ventilation variables between the beginning of optimum MFV settings and after $1 \mathrm{~h}$ (see Table 3). There was a nonsignificant reduction in $\mathrm{V}_{\mathrm{T}}$; associated with a nonsignificant increase in $\mathrm{P}_{\mathrm{aCO}}$. Lactate values decreased by $0.2 \mathrm{mg} / \mathrm{dL}$.

\section{Discussion}

The main finding of our study is that MFV allows the use of a higher breathing frequency and lower $\mathrm{V}_{\mathrm{T}}$ than conventional lung-protective ventilation. These results are consistent with our previous theoretical work. ${ }^{2,3}$ We demonstrated that a simple manual algorithm allowed implementation of MFV with a conventional ventilator.

MFV allows the delivery of ventilation at a range of frequencies that are above what clinicians typically use. 
Table 2. Differences of Ventilation and Hemodynamic Outcomes Between Conventional Ventilation and Optimum Settings Using the MFV Algorithm

\begin{tabular}{|c|c|c|c|c|}
\hline & $\begin{array}{l}\text { Conventional Ventilation } \\
\quad(\text { mean } \pm \mathrm{SD})\end{array}$ & $\begin{array}{l}\text { Optimum MFV } \\
(\text { mean } \pm \text { SD)* }\end{array}$ & $\begin{array}{c}\text { Change } \\
\text { (mean } \pm \mathrm{SD})\end{array}$ & $P \dagger$ \\
\hline \multicolumn{5}{|l|}{ Ventilation } \\
\hline Ventilatory frequency (breaths/min) & $32.1 \pm 6.8$ & $55.7 \pm 15.8$ & $23.7 \pm 17.6$ & .04 \\
\hline $\mathrm{V}_{\mathrm{T}}(\mathrm{mL} / \mathrm{kg})$ & $6.1 \pm 0.5$ & $5.2 \pm 0.8$ & $-1.0 \pm 0.7$ & .05 \\
\hline MV (L/min) & $1.9 \pm 0.4$ & $2.8 \pm 1.0$ & $0.9 \pm 1.1$ & .17 \\
\hline $\mathrm{PIP}\left(\mathrm{cm} \mathrm{H}_{2} \mathrm{O}\right)$ & $23.1 \pm 2.0$ & $25.8 \pm 4.8$ & $2.7 \pm 3.7$ & .17 \\
\hline$\overline{\mathrm{P}}_{\mathrm{aw}}\left(\mathrm{cm} \mathrm{H}_{2} \mathrm{O}\right)$ & $16.1 \pm 1.3$ & $16.4 \pm 2.0$ & $0.2 \pm 1.6$ & .75 \\
\hline Auto-PEEP $\left(\mathrm{cm} \mathrm{H}_{2} \mathrm{O}\right)$ & $0.6 \pm 0.9$ & $2.4 \pm 1.1$ & $1.8 \pm 0.5$ & .02 \\
\hline PEEP $\left(\mathrm{cm} \mathrm{H}_{2} \mathrm{O}\right)$ & $9.2 \pm 0.5$ & $10.6 \pm 1.2$ & $1.5 \pm 1.3$ & .03 \\
\hline \multicolumn{4}{|l|}{ Hemodynamics } & $\mathrm{P} \dagger$ \\
\hline Heart rate (beats/min) & $112.6 \pm 37.1$ & $158.9 \pm 55.2$ & $46.3 \pm 62.8$ & .34 \\
\hline Mean arterial pressure $(\mathrm{mm} \mathrm{Hg})$ & $88.9 \pm 10.7$ & $86.9 \pm 30.7$ & $-2.0 \pm 24.7$ & .76 \\
\hline Mean pulmonary artery pressure $(\mathrm{mm} \mathrm{Hg})$ & $29.3 \pm 6.6$ & $29.7 \pm 6.8$ & $0.4 \pm 7.5$ & .28 \\
\hline Central venous pressure $(\mathrm{mm} \mathrm{Hg})$ & $5.8 \pm 3.2$ & $5.2 \pm 2.6$ & $-0.6 \pm 1.3$ & .03 \\
\hline Pulmonary artery occlusion pressure $(\mathrm{mm} \mathrm{Hg})$ & $6.0 \pm 2.9$ & $5.2 \pm 3.3$ & $-0.8 \pm 0.4$ & .80 \\
\hline Cardiac output $(\mathrm{L} / \mathrm{min})$ & $1.4 \pm 0.7$ & $1.5 \pm 0.4$ & $0.1 \pm 0.5$ & .65 \\
\hline \multicolumn{5}{|l|}{ Blood analysis } \\
\hline $\mathrm{pH}$ & $7.33 \pm 0.05$ & $7.32 \pm 0.11$ & $0.00 \pm 0.13$ & .24 \\
\hline $\mathrm{P}_{\mathrm{aCO}_{2}}(\mathrm{~mm} \mathrm{Hg})$ & $50.2 \pm 8.5$ & $51.7 \pm 17.4$ & $1.6 \pm 16.4$ & .47 \\
\hline $\mathrm{P}_{\mathrm{aO}_{2}}(\mathrm{~mm} \mathrm{Hg})$ & $398.3 \pm 117.4$ & $404.2 \pm 85.9$ & $5.8 \pm 130.7$ & .35 \\
\hline $\mathrm{HCO}_{3}^{-}(\mathrm{mEq} / \mathrm{L})$ & $26.1 \pm 4.9$ & $25.7 \pm 2.7$ & $-0.5 \pm 4.7$ & .64 \\
\hline Lactate $(\mathrm{mg} / \mathrm{dL})$ & $0.9 \pm 0.6$ & $0.5 \pm 0.2$ & $-0.4 \pm 0.6$ & .20 \\
\hline $\mathrm{S}_{\overline{\mathrm{v}}_{2}}(\%)$ & $78.7 \pm 8.9$ & $78.7 \pm 7.2$ & $0.0 \pm 8.0$ & .45 \\
\hline Hemoglobin (g/dL) & $7.8 \pm 1.0$ & $7.4 \pm 0.8$ & $-0.2 \pm 1.4$ & .59 \\
\hline $\begin{array}{l}\text { * Results after } 1 \mathrm{~h} \text { of mid-frequency ventilation }(\mathrm{MFV}) \text {. } \\
\dagger \text { Results for ventilation outcomes from Wilcoxon signed-rank test } \\
\mathrm{V}_{\mathrm{T}}=\text { tidal volume } \\
\mathrm{MV}=\text { minute ventilation } \\
\mathrm{PIP}=\text { peak inspiratory pressure (above atmospheric pressure) } \\
\overline{\mathrm{P}}_{\mathrm{aw}}=\text { mean airway pressure } \\
\mathrm{S}_{\mathrm{V}_{2} \mathrm{O}_{2}}=\text { mixed venous oxygen saturation }\end{array}$ & observations; results for hemodynam & d analysis from regres: & $\mathrm{g}$ for baseline. & \\
\hline
\end{tabular}

Conventional practice limits frequency due to concerns about the development of auto-PEEP and its adverse hemodynamic effects. ${ }^{10,15,16}$ However, MFV is different from conventional CMV with regard to the development of frequency-related auto-PEEP. In conventional ventilation, when keeping all variables constant and increasing frequency, auto-PEEP rises exponentially to very high values, but only slightly in MFV. In a similar fashion, mean airway pressure rises exponentially to very high values for conventional ventilation, but does not change with frequency for MFV (Fig. 2, unpublished simulator data). This is why conventional ventilation is limited to relatively low frequencies (due to the hemodynamic consequences of auto-PEEP and mean airway pressure), whereas MFV can use a wider range of frequencies.

In this context, MFV allows the exploration of all ranges of ventilatory frequencies. The current paradigm limits ventilation to frequencies below 35 breaths/min in adults and 60 breaths/min in infants using conventional modes. ${ }^{11,17-21}$ Indeed, this recommendation makes sense when maintaining a relatively constant $\mathrm{V}_{\mathrm{T}} \cdot{ }^{15,22}$ However, our study demonstrates that the MFV strategy allows the clinician to provide higher frequencies. More importantly, our data are in keeping with data generated from neonatal studies in which conventional ventilation applied at higher breathing frequencies with pressure control ventilation (similar to MFV) led to improved ventilation outcomes. ${ }^{23,24}$

Our study demonstrated an increase in heart rate during the application of MFV, which, although not statistically significant, raises the concern for a decrease in stroke volume. Given the lower central venous pressure, stable airway, and pulmonary pressures, we suspect the cause was hypovolemia (decreasing central venous pressure through the study). Nonetheless, it is possible that the hemodynamic monitoring did not detect or was not capable of detecting a difference.

Our study also adds a description of the rate-related derecruitment. This event develops mainly at higher ventilatory frequencies, although it can happen at lower frequencies (but still $>35$ breaths $/ \mathrm{min}$ ) in the presence of lung injury. We 
Table 3. Differences of Ventilation and Hemodynamic Outcomes Between Mid-Frequency Ventilation at Optimal Settings and After $1 \mathrm{~h}$

\begin{tabular}{|c|c|c|c|c|}
\hline & $\begin{array}{l}\text { Initial Optimal Settings } \\
\quad(\text { mean } \pm \text { SD })\end{array}$ & $\begin{array}{c}\text { After } 1 \mathrm{~h} \\
(\text { mean } \pm \mathrm{SD})\end{array}$ & $\begin{array}{c}\text { Change } \\
(\text { mean } \pm \mathrm{SD})\end{array}$ & $P^{*}$ \\
\hline \multicolumn{5}{|l|}{ Ventilation } \\
\hline $\mathrm{V}_{\mathrm{T}}(\mathrm{mL} / \mathrm{kg})$ & $5.5 \pm 0.7$ & $5.2 \pm 0.8$ & $0.4 \pm 0.7$ & .17 \\
\hline MV (L/min) & $3.0 \pm 0.7$ & $2.8 \pm 1.0$ & $0.2 \pm 0.4$ & .25 \\
\hline PIP $\left(\mathrm{cm} \mathrm{H}_{2} \mathrm{O}\right)$ & $26.0 \pm 4.8$ & $25.8 \pm 4.8$ & $0.2 \pm 1.1$ & .35 \\
\hline$\overline{\mathrm{P}}_{\mathrm{aw}}\left(\mathrm{cm} \mathrm{H}_{2} \mathrm{O}\right)$ & $16.2 \pm 2.2$ & $16.4 \pm 2.0$ & $-0.1 \pm 0.5$ & .60 \\
\hline PEEP $\left(\mathrm{cm} \mathrm{H}_{2} \mathrm{O}\right)$ & $10.7 \pm 1.3$ & $10.6 \pm 1.2$ & $0.0 \pm 0.5$ & .60 \\
\hline \multicolumn{5}{|l|}{ Hemodynamics } \\
\hline Heart rate (beats/min) & $176.5 \pm 55.3$ & $158.9 \pm 55.2$ & $17.6 \pm 26.6$ & .25 \\
\hline Mean arterial pressure $(\mathrm{mm} \mathrm{Hg})$ & $86.2 \pm 11.5$ & $86.9 \pm 30.7$ & $-0.7 \pm 21.1$ & .60 \\
\hline Mean pulmonary artery pressure $(\mathrm{mm} \mathrm{Hg})$ & $29.0 \pm 5.0$ & $29.7 \pm 6.8$ & $-0.7 \pm 2.9$ & .46 \\
\hline Central venous pressure $(\mathrm{mm} \mathrm{Hg})$ & $5.6 \pm 3.2$ & $5.2 \pm 2.6$ & $0.3 \pm 1.5$ & $>.99$ \\
\hline \multicolumn{5}{|l|}{ Blood analysis } \\
\hline $\mathrm{pH}$ & $7.38 \pm 0.05$ & $7.32 \pm 0.11$ & $0.05 \pm 0.07$ & .12 \\
\hline $\mathrm{P}_{\mathrm{CO}_{2}}(\mathrm{~mm} \mathrm{Hg})$ & $46.2 \pm 7.8$ & $51.7 \pm 17.4$ & $-5.6 \pm 11.0$ & .17 \\
\hline $\mathrm{P}_{\mathrm{O}_{2}}(\mathrm{~mm} \mathrm{Hg})$ & $426.2 \pm 81.2$ & $404.2 \pm 85.9$ & $22.0 \pm 67.7$ & .35 \\
\hline $\mathrm{HCO}_{3}(\mathrm{mEq} / \mathrm{L})$ & $27.0 \pm 2.6$ & $25.7 \pm 2.7$ & $1.3 \pm 2.7$ & .35 \\
\hline Lactate $(\mathrm{mg} / \mathrm{dL})$ & $0.7 \pm 0.2$ & $0.5 \pm 0.2$ & $0.2 \pm 0.2$ & .05 \\
\hline \multicolumn{5}{|l|}{$\begin{array}{l}\text { * Results from Wilcoxon signed-rank test for paired observations } \\
\mathrm{V}_{\mathrm{T}}=\text { tidal volume } \\
\mathrm{MV}=\text { minute ventilation } \\
\mathrm{PIP}=\text { peak inspiratory pressure (above atmospheric pressure) } \\
\overline{\mathrm{P}}_{\mathrm{aw}}=\text { mean airway pressure. }\end{array}$} \\
\hline
\end{tabular}

speculate the rate-related de-recruitment is a manifestation of inappropriate PEEP and cyclic recruitment by $\mathrm{V}_{\mathrm{T}}$. During a tidal breath (more so with an inappropriately low PEEP), lung recruitment occurs throughout the inspiratory time. ${ }^{25-27}$ In MFV, as frequency increases, inspiratory time and $\mathrm{V}_{\mathrm{T}}$ decrease. Thus, ongoing cyclic recruitment may be lost despite an unchanging mean airway pressure and the presence of auto-PEEP. At some point, the gradual de-recruitment reaches a threshold below which a cascade of lung collapse occurs. The sudden de-recruitment further decreases $\mathrm{V}_{\mathrm{T}}$, leading to more lung collapse. The concept is similar to what may happen with high-frequency oscillatory ventilation, where a de-recruitment event manifests as loss in ventilation. ${ }^{28} \mathrm{Re}$ cruitment and PEEP always lead to its resolution. Perhaps at higher frequencies, there needs to be a prophylactic increase in PEEP. However, this is only a hypothesis, which requires further testing.

A concern regarding ventilation at higher frequencies is the potential increase in lung injury due to repeated exposure to injurious ventilatory cycles. This has been examined in several studies ${ }^{29-31}$ most recently by Vaporidi et al. ${ }^{32}$ They demonstrated a correlation with lung injury in a mouse model. However and most importantly, they also concluded that the injury was prevented with a concomitant decrease in $\mathrm{V}_{\mathrm{T}} \cdot 29,30$ In support of this, Conrad et al ${ }^{30}$ found that, at a normal $V_{T}$ $(5 \mathrm{~mL} / \mathrm{kg})$ versus a high $(20 \mathrm{~mL} / \mathrm{kg}) \mathrm{V}_{\mathrm{T}}$, the cyclic stretch did not induce injury across a range of breathing frequencies.
Our study has several limitations. Our pig model of lung injury may not be a clinical representation of lung injury. Furthermore, it is a known model, which may improve with time. ${ }^{33}$ However, $\mathrm{V}_{\mathrm{T}}$ and lung compliance remained stable through the study, suggesting no improvement in the lung conditions. Although the $\mathrm{P}_{\mathrm{aO}_{2}} / \mathrm{F}_{\mathrm{IO}_{2}}$ argues against the presence of lung injury, we did postmortem histological evaluation of the lungs (for control), and all had evidence of lung injury. Further studies should focus on evaluation of cytokines, comparative histological damage, and effect of time on MFV. Furthermore, the $\mathrm{V}_{\mathrm{T}}$ in pigs required for lung protection is not necessarily the $6 \mathrm{~mL} / \mathrm{kg} /$ ideal body weight we use in humans. ${ }^{34}$ However, we wanted to replicate the conditions seen in current practice and evaluate the effects of MFV on hemodynamics and ventilation rather than on lung injury. Another limitation (or rather aberration) is that our pigs demonstrated higher than expected pulmonary pressures..$^{35,36} \mathrm{We}$ repeatedly revised the systems and calibrated the system before each study. We found that the pulmonary artery catheter flush system caused a rise in pressure due to the constant flow of flush solution and the small diameter of the catheter lumen. We believe that this did not affect our results, as the artifact was present throughout the experiment, and the waveforms changed appropriately with clinical condition. Finally, the algorithm used $\mathrm{P}_{\mathrm{aCO}_{2}}$ to direct management of MFV. Although this may not seem clinically fea- 
A
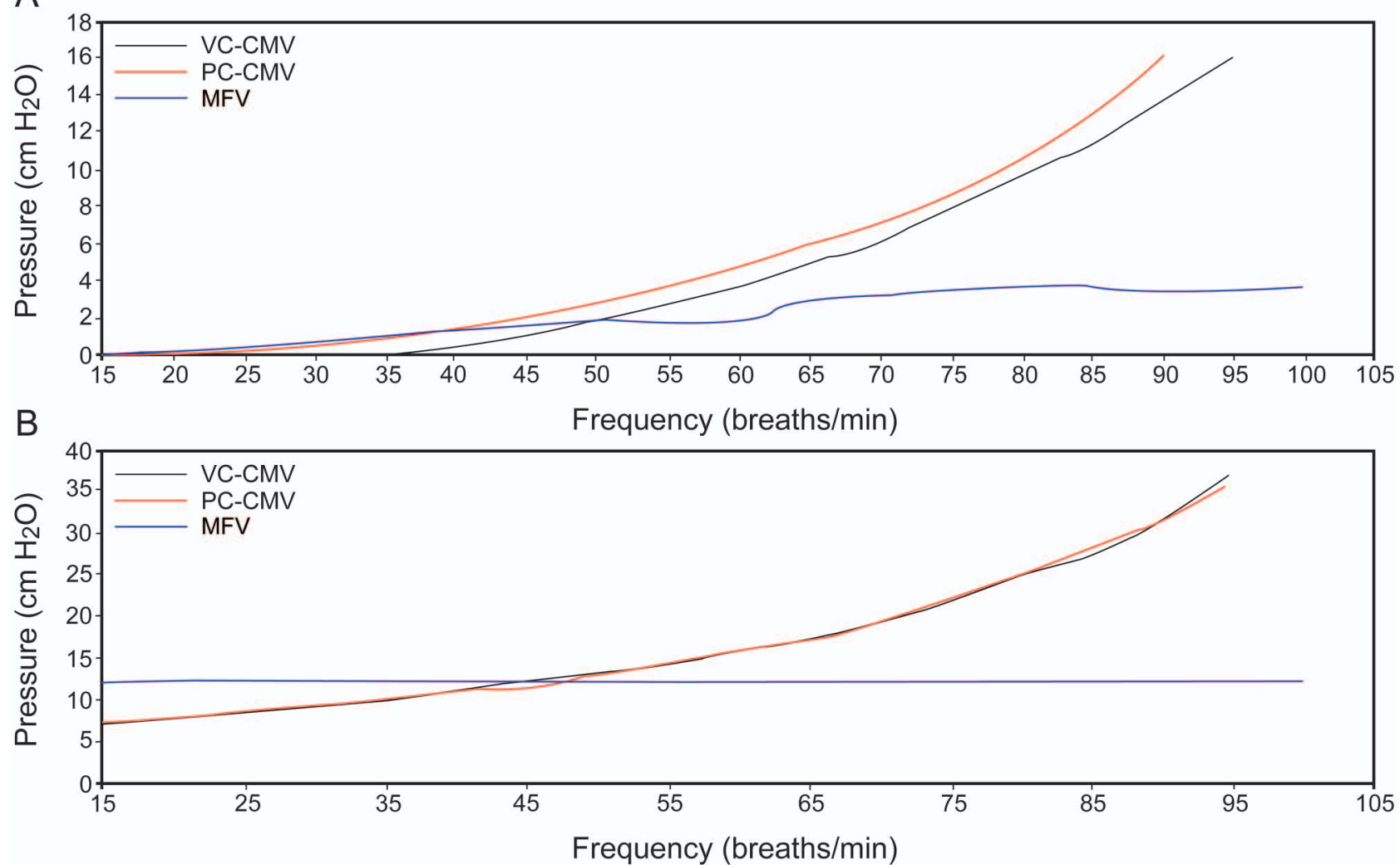

Fig. 2. Difference between mid-frequency ventilation (MFV), volume control continuous mandatory ventilation (VC-CMV), and pressure control CMV (PC-CMV) when frequency is increased. The figure shows a graphical representation of the results of a physical lung simulator (ASL 5000, IngMar Medical, Pittsburgh, Pennsylvania) ventilated at increasing frequency with volume control CMV, pressure control CMV, and MFV. For all modes, the frequency was increased (with all other settings held constant) from 15 to 90 breaths/min. A: auto-PEEP. B: mean airway pressure.

sible, this was a pilot trial. We envision that MFV would be programmed into the ventilator to drive an optimal targeting scheme. ${ }^{1}$ Other signals, such as end-tidal carbon dioxide or transcutaneous signals, could be used to give feedback on minute ventilation. From the practical standpoint, all this can be accomplished within the current constraint imposed by the Food and Drug Administration of maximum conventional ventilatory frequency of 150 breaths/min. MFV opens a range of capabilities for current critical care ventilators without the need for specialized equipment.

Our results must be interpreted with caution. The development of a mode of mechanical ventilation needs to move from the theoretical background to animal application to technological development and clinical application. These steps are essential for understanding what the mode does. We have developed the theoretical background in other studies; the goal of this study was to assess feasibility and hemodynamic effects in vivo. There are several other areas to assess. We have not evaluated the application of MFV in the presence of spontaneous breathing. As this is a pressure control mode, spontaneous breaths could cause larger $\mathrm{V}_{\mathrm{T}}$, asynchrony, and higher auto-PEEP. We need to assess other algorithms, feed- back loops, and effects on lung injury. Further research needs to be performed on MFV as a ventilatory mode before it can be applied clinically.

\section{Conclusions}

In this pilot study, we demonstrated that MFV allows the use of higher breathing frequencies and lower $\mathrm{V}_{\mathrm{T}}$ than conventional ventilation. We described the effects on gas exchange, airway pressures, and potential issues with derecruitment. We also demonstrated the feasibility of a decision support algorithm to manage MFV.

\section{REFERENCES}

1. Chatburn RL, Mireles-Cabodevila E. Closed-loop control of mechanical ventilation: description and classification of targeting schemes. Respir Care 2011;56(1):85-102.

2. Mireles-Cabodevila E, Diaz-Guzman E, Arroliga AC, Chatburn RL. Human versus computer controlled selection of ventilator settings: an evaluation of adaptive support ventilation and mid-frequency ventilation. Crit Care Res Pract 2012;2012:204314.

3. Mireles-Cabodevila E, Chatburn RL. Mid-frequency ventilation: unconventional use of conventional mechanical ventilation as a lungprotection strategy. Respir Care 2008;53(12):1669-1677. 


\section{Mid-Frequency Ventilation in an Animal Model of Lung InJury}

4. Marini JJ, Crooke PS 3rd. A general mathematical model for respiratory dynamics relevant to the clinical setting. Am Rev Respir Dis 1993;147(1):14-24.

5. Marini JJ, Crooke PS 3rd, Truwit JD. Determinants and limits of pressure-preset ventilation: a mathematical model of pressure control. J Appl Physiol 1989;67(3):1081-1092.

6. Radford EP Jr. Ventilation standards for use in artificial respiration. J Appl Physiol 1955;7(4):451-460.

7. Chakrabarti MK, Gordon G, Whitwam JG. Relationship between tidal volume and deadspace during high frequency ventilation. Br J Anaesth 1986;58(1):11-17.

8. Mireles-Cabodevila E, Chatburn RL. Mid-frequency ventilation: theoretical basis and clinical predictions. American Thoracic Society International Conference, Am J Respir Crit Care Med, Apr 2008;177

9. Mireles-Cabodevila E, Diaz-Guzman E, Chatburn RL. Human vs machine selection of ventilator settings: evaluation of adaptive support ventilation and mid-frequency ventilation. Chest 2008;134(4, meeting abstracts):s18003.

10. Vieillard-Baron A, Jardin F. The issue of dynamic hyperinflation in acute respiratory distress syndrome patients. Eur Respir J 2003; 22(Suppl 42):43s-47s.

11. Spitzer AR, Clark RH. Positive-pressure ventilation in the treatment of neonatal lung disease. In: Goldsmith JP, Karotkin EH, editors. Assisted ventilation of the neonate. St. Louis: Saunders Elsevier, 2011;163-185.

12. Bernhard WN, Yost L, Joynes D, Cothalis S, Turndorf H. Intracuff pressures in endotracheal and tracheostomy tubes: related cuff physical characteristics. Chest 1985;87(6):720-725.

13. Hanson A, Göthberg S, Nilsson K, Larsson LE, Hedenstierna G. $\mathrm{VTCO}_{2}$ and dynamic compliance-guided lung recruitment in surfactant-depleted piglets: a computed tomography study. Pediatr Crit Care Med 2009;10(6):687-692.

14. Schmalisch G, Schmidt M, Proquitté H, Foitzik B, Rüdiger M, Wauer RR. Measurement of changes in respiratory mechanics during partial liquid ventilation using jet pulses. Crit Care Med 2003;31(5):1435-1441.

15. Vieillard-Baron A, Prin S, Augarde R, Desfonds P, Page B, Beauchet $\mathrm{A}$, Jardin $\mathrm{F}$. Increasing respiratory rate to improve $\mathrm{CO}_{2}$ clearance during mechanical ventilation is not a panacea in acute respiratory failure. Crit Care Med 2002;30(7):1407-1412.

16. Richard JC, Brochard L, Breton L, Aboab J, Vandelet P, Tamion F, et al. Influence of respiratory rate on gas trapping during low volume ventilation of patients with acute lung injury. Intensive Care Med 2002;28(8):1078-1083.

17. Meade MO, Cook DJ, Guyatt GH, Slutsky AS, Arabi YM, Cooper DJ, et al. Ventilation strategy using low tidal volumes, recruitment maneuvers, and high positive end-expiratory pressure for acute lung injury and acute respiratory distress syndrome: a randomized controlled trial. JAMA 2008;299(6):637-645.

18. Mercat A, Richard JC, Vielle B, Jaber S, Osman D, Diehl JL, et al. Positive end-expiratory pressure setting in adults with acute lung injury and acute respiratory distress syndrome: a randomized controlled trial. JAMA 2008;299(6):646-655.

19. National Heart, Lung, and Blood Institute Acute Respiratory Distress Syndrome (ARDS) Clinical Trials Network, Wiedemann HP, Wheeler AP, Bernard GR, Thompson BT, Hayden D, et al. Comparison of two fluid-management strategies in acute lung injury. N Engl J Med 2006;354(24):2564-2575.

20. Hess D, MacIntyre NR, Mishoe SC, Gavin WF, Adams AB, editors. Respiratory care: principles and practice. Sudbury, Massachusetts: Jones and Bartlett Learning; 2012.

21. Greenough A, Dimitriou G, Prendergast M, Milner AD. Synchronized mechanical ventilation for respiratory support in newborn infants. Cochrane Database Syst Rev 2008(1):CD000456.

22. Reynolds EO. Effect of alterations in mechanical ventilator settings on pulmonary gas exchange in hyaline membrane disease. Arch Dis Child 1971;46(246):152-159.

23. Greenough A, Greenall F. Performance of respirators at fast rates commonly used in neonatal intensive care units. Pediatr Pulmonol 1987;3(5):357-361

24. Greenough A, Pool J, Greenall F, Morley C, Gamsu H. Comparison of different rates of artificial ventilation in preterm neonates with respiratory distress syndrome. Acta Paediatr Scand 1987;76(5):706-712.

25. Gattinoni L, Caironi P, Pelosi P, Goodman LR. What has computed tomography taught us about the acute respiratory distress syndrome? Am J Respir Crit Care Med 2001;164(9):1701-1711.

26. Jonson B, Richard JC, Straus C, Mancebo J, Lemaire F, Brochard L. Pressure-volume curves and compliance in acute lung injury: evidence of recruitment above the lower inflection point. Am J Respir Crit Care Med 1999;159(4 Pt 1):1172-1178.

27. Pelosi P, Goldner M, McKibben A, Adams A, Eccher G, Caironi P, et al. Recruitment and derecruitment during acute respiratory failure: an experimental study. Am J Respir Crit Care Med 2001;164(1):122-130.

28. Kubiak BD, Albert SP, Gatto LA, Trikha G, El-Zammar O, Nieman GF. Loss of airway pressure during HFOV results in an extended loss of oxygenation: a retrospective animal study. J Surg Res 2010; 162(2):250-257.

29. Bshouty Z, Younes M. Effect of breathing pattern and level of ventilation on pulmonary fluid filtration in dog lung. Am Rev Respir Dis 1992;145(2 Pt 1):372-376.

30. Conrad SA, Zhang S, Arnold TC, Scott LK, Carden DL. Protective effects of low respiratory frequency in experimental ventilator-associated lung injury. Crit Care Med 2005;33(4):835-840.

31. Rich PB, Reickert CA, Sawada S, Awad SS, Lynch WR, Johnson KJ, Hirschl RB. Effect of rate and inspiratory flow on ventilatorinduced lung injury. J Trauma 2000;49(5):903-911.

32. Vaporidi K, Voloudakis G, Priniannakis G, Kondili E, Koutsopoulos A, Tsatsanis C, Georgopoulos D. Effects of respiratory rate on ventilator-induced lung injury at a constant $\mathrm{PaCO}_{2}$ in a mouse model of normal lung. Crit Care Med 2008;36(4):1277-1283.

33. Matute-Bello G, Frevert CW, Martin TR. Animal models of acute lung injury. Am J Physiol 2008;295(3):L379-L399.

34. Protti A, Cressoni M, Santini A, Langer T, Mietto C, Febres D, et al. Lung stress and strain during mechanical ventilation: any safe threshold? Am J Respir Crit Care Med 2011;183(10):1354-1362.

35. Hakim TS, Picone A, Oleary CE, Camporesi EM. Protamine-induced pulmonary venoconstriction in heparinized pigs. Anesth Analg 1995;81(1):38-43.

36. Sproul A, Simpson E. Stroke volume and related hemodynamic data in normal children. Pediatrics 1964;33(6):912-918.

This article is approved for Continuing Respiratory Care Education credit. For information and to obtain your CRCE

(free to AARC members) visit www.rcjournal.com

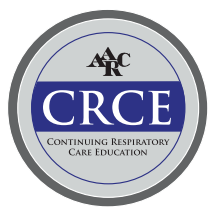

